\title{
O PRONATEC CAMPO E O CONTEXTO DO CAMPO E DA EDUCAÇÃO DO CAMPO NO BRASIL
}

\author{
THE PRONATEC CAMPO AND THE CONTEXT OF RURAL \\ EDUCATION IN THE BRAZIL
}

\author{
Marcio Adriano Azevedo ${ }^{1}$ \\ Shilton Roque dos Santos ${ }^{2}$
}

\begin{abstract}
RESUMO
O artigo analisa o contexto da construção e implementação do Pronatec Campo enquanto política de Educação Profissional do campo num quadro maior de disputa pela hegemonia do modelo de desenvolvimento do campo e de Educação do Campo. Trata-se de uma pesquisa bibliográfica e documental, que utiliza as categorias teóricas de hegemonia de Gramsci (1980), bem como de Escola Politécnica de Pystrak (2005), das concepções de Educação do Campo propostas na Conferência Nacional por uma Educação Básica do Campo (KOLING; NERY; MOLLINA, 1999), da análise histórica do contexto econômico, político e social do campo de Mazoyer e Roudart (2010), para analisar os documentos referentes ao Pronatec Campo e Pronacampo (BRASIL, 2013), concluindo que apesar de absorver demandas da população do campo essa política se aproxima muito mais das concepções de Educação Rural e do campo hegemônico do que de Educação do Campo e sua população.
\end{abstract}

Palavras-chave: Pronatec Campo; Educação do Campo; Educação Profissional.

\section{ABSTRACT}

The article analyzes the context of the construction and implementation of Pronatec Campo as a Technical Education policy of the field in a larger framework of dispute for the hegemony of the field development model and Rural Education. It is a bibliographical and documentary research that uses the theoretical categories of hegemony of Gramsci (1980), as well as of Polytechnic School of Pystrak (2005), of the conceptions of Field

\footnotetext{
${ }^{1}$ Doutor (2010) e Mestre (2006) em Educação (Política e Gestão), pela UFRN. Especialista em Processos Educacionais (2003) e graduado em Pedagogia (2000), também pela UFRN. Cursou estágio Pós-Doutoral (20132014) em Sociologia da Educação, pela Universidade do Minho/Portugal. É professor do Instituto Federal de Educação, Ciência e Tecnologia do Rio Grande do Norte - IFRN. Professor do Programa de Pós-Graduação em Educação Profissional - PPGEP/IFRN. Temas de interesse: Avaliação de políticas públicas, Educação profissional, Formação e trabalho docente, Educação do Campo e Povos Tradicionais, Educação de Jovens e Adultos, e pesquisa e inovação.

2 Mestrando do Programa de Pós-Graduação em Educação Profissional do Instituto Federal de Educação, Ciência e Tecnologia do Rio Grande do Norte. Possui graduação em Direito pela Universidade Federal do Rio Grande do Norte (2011). Advogado inscrito na OAB/RN sob o número de ordem 10.269. Atualmente é assistente em administração do Instituto Federal de Educação, Ciência e Tecnologia do Rio Grande do Norte e é pesquisador em Avaliação Política, Educação Profissional e Assistência Estudantil.
} 
Education proposed in the National Conference for a Basic Education of the Field (KOLING; NERY; MOLLINA, 1999), the historical analysis of the economic, political and social context of the Mazoyer and Roudart field (2010), to analyze the documents referring to Pronatec Campo and Pronacampo (BRAZIL, 2013), concluding that although to absorb demands of the landsman population this policy is much closer to the conceptions of Educação Rural and the hegemonic field than those of Educação do Campo and the ladnsman population.

Keywords: Pronatec Campo; Rural Education; Technical Education.

\section{INTRODUÇÃO E METODOLOGIA}

A construção e desenvolvimento do Programa Nacional de Acesso ao Ensino Técnico e Emprego no Campo (Pronatec Campo), enquanto política pública para a Educação Profissional do Campo e seu contexto político social, num quadro de disputa por hegemonia entre o agronegócio e a população do campo é o objeto de análise no presente artigo.

Para a realização deste, adotamos como metodologia uma revisão bibliográfica partindo dos princípios e concepções para uma Educação Básica do Campo, propostos na Conferência Nacional por uma Educação Básica do Campo (KOLING; NERY; MOLLINA, 1999; ARROYO, 1999), da análise histórica do contexto econômico, político e social do campo de Mazoyer e Roudart (2010), dos conceitos de Escola Politécnica de Pystrak (2005) e de hegemonia em Gramsci (1980).

Adotamos, ainda, a análise documental na qual nos debruçamos sobre os documentos referentes ao Pronatec Campo e Programa Nacional de Educação do Campo (Pronacampo) (BRASIL, 2013) e no Relatório do Fórum Nacional da Educação do Campo (FONEC) de 2012 (BRASIL, 2012) que analisa a situação do campo no Brasil nos últimos anos.

O Pronatec Campo se insere em um contexto político de contradições, de avanços e retrocessos das demandas históricas da população do campo, dentre elas a Educação do Campo. Contexto de contradições no qual está imerso o Estado brasileiro no circuito histórico em que foi implantado o Pronatec Campo (de 2012 a 2016), nesse sentido, este artigo tenta responder onde esta política se situa nesse quadro de contradições. Este artigo é o recorte de uma pesquisa mais ampla intitulada: Avaliação Participativa de Resultados Sociais do Pronatec Campo (SANTOS, 2018). 


\section{DISCUSSÃO TEÓRICA E ANÁLISE}

O Pronatec Campo, diferente do Pronatec Geral é uma política pública demandada pelo Ministério do Desenvolvimento Agrário (MDA) que tem a tarefa, nesta política, de articular as bases para a formação profissional no campo, portanto, podemos considerar que se trata de educação profissional direcionadas para sujeitos que vivem no campo. Ao MDA cabe levantar quais cursos essa população tem interesse e quais sujeitos desejam participar desses cursos de formação profissional. Tem como missão, ainda, fazer a ligação entre esta demanda e o Ministério da Educação (MEC) e as instituições ofertantes dos cursos para materializar tal oferta.

Esta política tem como objetivo "[...] promover espaços de qualificação profissional de agricultores e agricultoras, integrando às demais políticas de desenvolvimento rural sustentável e solidário" (BRASIL, 2013). Essa apresenta como público-alvo, que aqui chamaremos de sujeitos-beneficiários, os povos camponeses, sendo o sentido de camponês aquele dado pelos próprios trabalhadores do campo, demarcado no documento: "Por uma Educação Básica do Campo" (KOLING; NERY; MOLLINA, 1999). Seria a educação do povo que tenta garantir a sobrevivência a partir do trabalho no campo, assalariados do campo, camponeses, quilombolas e indígenas. Seria uma Educação do Campo para os "[...] diversos tipos de assalariados vinculados à vida e ao trabalho no meio rural" (KOLING; NERY; MOLLINA, 1999, p. 26). A isso, podemos chamar de campo contra-hegemônico do campo brasileiro, tomando o conceito de hegemonia de Gramsci (1980).

Para além do objetivo geral do Pronatec Campo é interessante destacar que seus objetivos específicos estão vinculados às demandas desse campo contra-hegemônico para o campo brasileiro, como por exemplo: princípios da agroecologia como forma de desenvolvimento rural sustentável; promoção de processos de diversificação da produção; e preocupação com a segurança alimentar e nutricional da comunidade (BRASIL, 2013). Esses, portanto, são objetivos opostos às características do desenvolvimento do agronegócio brasileiro, que constitui o campo hegemônico no processo de disputa por um modelo de trabalho no campo em nosso país. 
Ainda na perspectiva das distinções entre Pronatec Campo e Pronatec Geral, na dimensão de análise de uma intervenção pública, proposta por Cotta (1998), aquela que analisa esta conforme a relação entre Plano, Programa e Projeto, o Pronatec Campo faz parte do Pronacampo. Programa instituído pelo Decreto n 7.352, de 4 de novembro de 2010, e tem como objetivo ampliar e qualificar a oferta da Educação Básica e Superior do Campo.

Para analisarmos o Pronatec Campo na forma como se apresenta, como fenômeno, no plano formal da política, essa forma aparenta diferir bastante do Pronatec Geral. A análise deste último enquanto instrumento de propagação da hegemonia do capital e de suas demandas para a educação profissional faz parte do papel do pesquisador em uma ação de ir a fundo em suas análises, para superar o senso comum, pois é imprescindível à suspeição ideológica (SOUZA, 2014), principalmente em avaliações de políticas públicas. Dessa maneira, para aqueles que como nós optam pelo método materialista-histórico-dialético é necessário analisar criticamente o objeto pesquisado antes de expô-lo, pois, segundo o próprio Marx (2008) se as aparências dos objetos coincidissem com sua essência, toda ciência seria supérflua.

Nesse sentido, por coerência com nossa proposta e com a metodologia adotada, é necessário analisar o contexto em que se insere a política em questão e as determinações históricas decorrentes do momento anterior a sua formulação e implementação.

O Campo enquanto espaço social não pode ser analisado de forma isolada, ele faz parte do desenvolvimento da sociedade; faz parte do desenvolvimento do capital e das forças produtivas; faz parte da história de um povo com suas lutas e contradições. Nesse sentido, é importante situar o Campo nesses processos. Em trabalho anterior (SANTOS, 2018), apresentamos a Educação Profissional e o Pronatec a partir de um processo de desenvolvimento de avanço do neoliberalismo no Brasil e no mundo. Analisamos este tendo como parâmetro a crise do capital da década de 1970 e as mudanças advindas do desenvolvimento do modo de produção flexível, da forma Estado que atendeu a tal finalidade, e por fim, da perspectiva de educação profissional formada hegemonicamente a partir deste. Ao tratarmos da avaliação de políticas públicas, discorremos sobre a transformação dessa como subcampo por meio das mudanças decorrentes da nova forma de produção e 
acumulação e das consequências políticas desta para a sociedade, levando a uma aproximação da avaliação ao processo de contrarreforma do Estado, atendendo a interesses neoliberais e focada na racionalidade do gasto público, principalmente o social.

O Campo também passou por transformações decorrentes da nova forma de produção e acumulação do capital em sua fase de reorganização deste frente à crise dos anos de 1970.

Apesar do nosso recorte temporal de análise, é importante destacar que Marx e Engels (2008) em o Manifesto Comunista de 1848 já atentavam para o movimento de subordinação do campo à cidade de responsabilidade da burguesia, com a criação de cidades enormes, aumentando suas populações e arrancando os povos do campo. Tudo isso, como parte da formatação de Estado mais adequada à expansão dos interesses dessa classe, pois, a burguesia demandava um Estado centralizado para suprimir a dispersão dos meios de produção, o mesmo fez com as cidades, inflando-as ao custo da retirada dos povos do campo.

O período que antecedeu a crise dos anos 1970 é central para entendermos o desenvolvimento do processo de expulsão dos povos campesinos de suas terras nos países subdesenvolvidos, bem como do desemprego estrutural no campo e na cidade como vemos no Brasil do período em estudado neste artigo.

O processo de modernização agrícola ocorrido nos países desenvolvidos, vinculado ao processo de mundialização da economia, teve como consequências uma redução dos preços dos produtos agrícolas, conforme Mazoyer e Roudart (2010), o que por sua vez, gerou nos países que essencialmente exportavam produtos agrícolas e importavam produtos manufaturados um grande déficit em sua balança comercial.

Como a maioria destes países da periferia do capitalismo herdara historicamente uma agricultura subequipada (MAZOYER; ROUDART, 2010) e parte dos seus governantes compreendiam que a razão do seu subdesenvolvimento estava num atraso técnico e estrutural, passaram a investir na modernização, a partir do Estado, na sua agricultura, e também na qualificação profissional dos trabalhadores. O que por sua vez fora concebida nos moldes dos países industrializados, o que necessariamente gerou importações de máquinas e serviços técnicos de instrução desses países, convergindo para um quadro de endividamento público desses países subdesenvolvidos. 


\section{norstat 0 \\ Debates Insubmissos}

Nesse cenário, chegamos ao ponto onde as instituições multilaterais como Fundo Monetário Internacional (FMI) e Banco Mundial realizaram empréstimos a esses países endividados, tendo como contrapartida, além da cobrança de juros a exigência de ajustes estruturais nas políticas daqueles Estados, ajustes estes no sentido da liberalização e da redução do gasto social.

É importante lembrar também que todo esse processo de modernização impulsionou o desemprego, uma vez que, agora máquinas ocupavam o trabalho de várias famílias camponesas, e em países como o Brasil em que a questão fundiária não fora resolvida, o desemprego se agravou. Assim, sem trabalho, os campesinos foram expulsos de suas terras e passaram a se deslocar para as cidades em busca de emprego. As cidades não estavam preparadas para tamanho fluxo migratório e assim foi ampliado o desemprego estrutural nas áreas urbanas.

Com a redução do gasto social somado aos altos índices de desemprego, a demanda por consumo foi caindo e empurrando o capital para mais uma de suas crises. Essa encontrara como saída o modelo da reestruturação produtiva, que tinha como suporte políticas de ordem neoliberal e neoconservadora que prediziam a redução de políticas públicas, o que no Brasil pós-ditadura civil/militar combinou a ausência de investimentos no campo com a baixa dos preços das exportações diante das políticas cambiais (BRASIL, 2012).

Todo esse processo de modernização e migração forçada, descrito de forma dolorosa pela literatura nacional e internacional ${ }^{3}$, inverteu em menos de 1950 o modo de vida em nosso país, o que ampliou a hegemonia da forma de vida da cidade sobre o campo, idealizando o campo como um espaço do atrasado, a ser substituído pelo moderno que seria o espaço das cidades.

\footnotetext{
${ }^{3}$ Morte e Vida Severina (MELO NETO, 2009) demonstra o sofrimento de um migrante brasileiro, nordestino, na década de 50, ao sair do campo e todo seu encontro com tragédias e morte nessa trajetória de sair do seu território rumo a cidade, que por si só é comparada a morte. Vinhas da Ira (STEINBECK, 1972), retrata o fluxo migratório rumo ao Oeste dos Estados Unidos no período da crise de 1929, a partir de uma viagem familiar com o encontro de tragédias e mortes, bem como o desemprego e a vida marginalizada na cidade. As duas obras são essenciais para a compreensão a partir da ótica dos sujeitos dos resultados sociais desse processo de modernização do campo atrelado ao desenvolvimento do capitalismo moderno.
} 
Apesar disso, não foi um processo sem contradições, em nosso país os povos campesinos organizaram-se durante décadas de resistência através de movimentos sociais, principalmente os de luta por terra, em torno de um projeto de campo para nosso país que a perspectiva da integração entre campo e cidade e não da superação daquele por este.

Diante da compreensão de que um projeto de campo e de país é perpassado também por um projeto de educação do campo, e conscientes de que é necessário que esse projeto emane do povo campesino, construído de acordo com suas necessidades e que traduza a sua realidade, foi construído e realizado o Encontro Nacional de Educadoras e Educadores da Reforma Agrária (I ENERA). Este evento foi promovido pelo Movimento dos Trabalhadores Rurais Sem Terra (MST), em julho de 1997, em Brasília em parceira com a Universidade de Brasília (UnB), Fundo das Nações Unidas para a Infância (Unicef), Organização das Nações Unidas para a Educação, a Ciência e a Cultura (Unesco) e Confederação dos Bispos do Brasil (CNBB). Neste evento se iniciou o processo de articulação e organização da I Conferência Nacional: Por uma Educação Básica do Campo, que ocorreu em Luziânia entre 27 e 30 de julho de 1998, promovida pela CNBB, Unicef, Unesco e UnB (KOLING; NERY; MOLLINA, 1999).

Esta I Conferência Nacional é um marco na organização dos povos do campo para a construção de um modelo contra-hegemônico, não só de educação do campo, mas também de campo e de país. Esta demonstrou o nível de organização e de resistência deste povo, o que se refletiu na elaboração de uma agenda de políticas públicas para o campo no sentido de possibilitar a transformação deste em um território que permitisse sua fixação, vida humanizada e repleta de possibilidades para esses povos.

Essa foi uma virada de paradigma na questão da Educação do Campo e do projeto de campo no desenvolvimento nacional. Virada, pois, no período anterior conhecido como o do Ruralismo Pedagógico, conforme nos assevera Silva (2017), a educação estava vinculada a um projeto de campo que defendia a vocação agrária do Brasil como modelo de crescimento do país, com foco no aumento da produtividade e no abastecimento das cidades. 
Esse movimento anterior de modernização conservadora aumentou o desemprego e tirou os povos do campo de seu espaço, criando, assim, uma imagem deformada do campo, e consequentemente de escola do campo.

O paradigma que se configurava até então apresentava uma tendência de superação do campo enquanto espaço de atraso, e por sua vez o povo campesino como resíduo deste: "Há uma tendência dominante em nosso país, marcado por exclusões e desigualdades, de considerar a maioria da população que vive no campo como parte atrasada e fora do lugar no almejado projeto de modernidade" (KOLING; NERY; MOLLINA, 1999 p. 20)

Para essa perspectiva e para as políticas neoliberais que avançavam, não fazia sentido investimento público em educação para os povos do campo. Isso gerou uma grande ausência por parte do Estado na Educação do Campo e produziu nessa Educação e no Campo uma imagem vinculada ao atraso. Essa coincidente com a visão de campo que tinha o projeto de nação em curso por parte das elites naquele período. Arroyo (1999), no segundo caderno resultado da I Conferência supracitada demonstra qual a imagem que se tinha até então das escolas do campo: "Em nossa história domina a imagem de que a escola no campo, tem que ser apenas a escolinha rural das primeiras letras. A escolinha cai não cai, onde uma professora que quase não sabe ler, ensina alguém a não saber quase ler" (ARROYO, 1999, p. 20).

Nesse sentido, a Educação do Campo ficou por muito tempo vinculada ao modelo de educação e de sociedade da cidade, sem considerar sua história, cultura e valores próprios, tendo como opção política por boa parte dos gestores públicos, o estímulo aos estudos na cidade, com ações de transporte escolar. Essas, muitas vezes, resultantes de moeda de troca por apoio político, em que as crianças, jovens e adultos, submetem-se a longos e desgastantes trajetos, para estudar em uma escola que difere em muito dos seus valores e necessidades.

Silva (2017), em sua tese, reforça essa questão ao demonstrar como "a figura socialmente construída sobre o campo como território do 'antigo', 'atrasado' e subordinado à cidade produziu, por muito tempo, a ideia de que a educação escolar no campo deveria seguir esse paradigma urbano" (SILVA, 2017, p. 34, grifos no original).

A mudança de paradigma que emerge nesta Conferência, vem no sentido da população do campo, enquanto resistente a essa tentativa de superação do campo, para demonstrar que o 


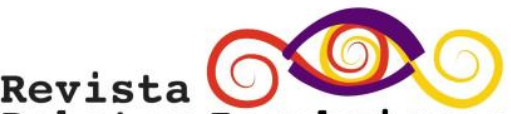 \\ Debates Insubmissos}

projeto das elites para o desenvolvimento desse e da sua educação não responde às suas demandas enquanto população.

Trata-se, então, de um momento político em que os povos do campo unificam um projeto de desenvolvimento do campo que exige o tratamento destes como sujeitos de um projeto de desenvolvimento e não como resíduo do processo de modernização (KOLING; NERY; MOLLINA, 1999). Um projeto que vincula uma política de segurança alimentar e de reforma agrária ocupando produtivamente o território, a uma proposta de Educação Básica do Campo para efetivar tudo isso.

Nesse sentido, os coletivos repolitizam à formação (ARROYO, 2008), exigindo não mais uma educação adaptável, mas, sim, construindo uma proposta que parte da sua diversidade. O primeiro caderno resultado dessa Conferência apresenta um conceito de Educação do Campo, baseado nessa diversidade:

A educação do campo precisa ser uma educação específica e diferenciada, isto é, alternativa. Mas, sobretudo, deve ser educação no sentido amplo de processo de formação humana que constrói referências culturais e políticas para a intervenção das pessoas e dos sujeitos sociais na realidade, visando a uma humanidade mais plena e feliz (KOLING; NERY; MOLLINA,1999, p. 24).

É importante, neste momento, frisar que essa mudança de paradigma, assinala também uma mudança etimológica e conceitual, o uso da expressão "do campo" e não mais "rural", posicionando esta proposta de desenvolvimento e de educação sob o recorte de classe dos povos do campo. Constituindo-se, então, como um instrumento de disputa de hegemonia. Temos, assim, mais um conceito de Educação do Campo, nessa perspectiva:

Entende-se por escola do campo aquela que trabalha desde os interesses, a política, a cultura e a economia dos diversos grupos de trabalhadores e trabalhadoras do campo, nas suas diversas formas de trabalho e de organização, na sua dimensão de permanente processo, produzindo valores, conhecimentos e tecnologias na perspectiva do desenvolvimento social e econômico igualitário da população. (KOLING; NERY; MOLLINA, 1999, p. 63).

No que diz respeito a essa demarcação conceitual, além da substituição do termo rural, a expressão do campo, no sentido da educação, amplia a perspectiva e o conceito desta para além da dimensão geográfica. Sendo possível observar no segundo caderno da Conferência, o seguinte conceito de Educação do Campo: 


\title{
noviste \\ Debates Insubmissos
}

\begin{abstract}
Uma escola do campo é a que defende os interesses, a política, a cultura e a economia da agricultura camponesa, que construa conhecimentos e tecnologias na direção do desenvolvimento social e econômico dessa população. A sua localização é secundária, o que importa são suas proximidades política e espacial com a realidade camponesa. (ARROYO; FERNANDES, 1999, p. 65).
\end{abstract}

Para este movimento é necessário transformar o papel da escola, assumindo um compromisso com a valorização da cultura dos povos do campo; democratizando-o em seu sentido mais amplo, ampliando acesso, qualidade e participação dos sujeitos; incorporando lições da educação popular; e um currículo que contemple a relação do trabalho com a terra (ARROYO, 1999). Essa deve ter como matrizes culturais a relação da criança, do homem e da mulher com a terra; o tempo da produção da vida coletiva, do espaço cultivado, humanizado (o tempo dos indivíduos vinculado ao tempo da natureza); celebração e transmissão da memória coletiva; e predomínio da oralidade (ARROYO, 1999).

A importância de matrizes curriculares próprias construídas a partir da realidade do campo foi centralidade também em um marcante movimento dos trabalhadores, ocorrido há um século, e que é inspiração até hoje nas lutas por transformação social, o período de transição na União Soviética. Pistrak (2005) ao apresentar os debates sobre a construção de uma Escola Politécnica assevera:

A escola politécnica [...], sendo, no seu fundamento, única, deve ter, partindo deste fato, diferentes matizes nas condições urbanas (na produção) e no campo (na agricultura). Temos, portanto, o direito de dizer que, em um período de transição a escola deve ter na cidade e no campo diferentes traços. Estes matizes, no nosso período não são apenas um detalhe, mas um momento muito importante que deve ter consequência em nossa política escolar. (PISTRAK, 2005, p. 42).

Com este sentido de valorização da cultura advinda das relações sociais fruto do trabalho da terra, teremos mais um conceito fundamental de Educação do Campo, sob o paradigma dos povos do campo:

[...] pensar uma proposta de desenvolvimento e de escola do campo que leve em conta a tendência de superação da dicotomia rural-urbano [...] ao mesmo tempo em que resguarde a identidade cultural dos grupos que ali produzem sua vida [...]. Nesse sentido, uma escola do campo não precisa ser uma escola agrícola, mas será necessariamente uma escola vinculada à cultura que se produz por meio das relações sociais mediadas pelo trabalho na terra (KOLING; NERY; MOLLINA, 1999, p. 37). 
Esse projeto de Educação do Campo, riquíssimo em possibilidades e vinculado ao desenvolvimento sustentável do Campo e de integração com o Urbano, tem uma característica muito forte que é a de vincular a educação aos direitos e aos movimentos sociais, afastando-a da sua vinculação direta com o mercado. Essa posição é mantida até hoje e vai ter importância central em nossa avaliação do Pronatec Campo.

Essa demarcação constitui-se também em uma crítica central às políticas e princípios do neoliberalismo. No segundo caderno da Conferência, Arroyo (1999) nos diz que:

O mercado nunca foi bom conselheiro para construir um projeto de educação básica. O movimento social é mais exigente. Porque nos situa no terreno dos direitos, nos leva a vincular educação com saúde, cooperação, justiça, cidadania. O direito coloca a educação no terreno dos grandes valores da vida e da formação humana. (ARROYO, 1999 p. 21-22)

Essa aproximação da educação com os direitos nos retoma as discussões de Haddad (2004), onde este afirma que a educação é um direito que nos abre as portas para os outros direitos, constituindo-se como um direito básico, não podendo ser tratado, como a Organização Mundial do Comércio (OMC) vem insistindo, como um produto.

Sob esses fundamentos, o segundo caderno fruto da Conferência já referenciada, apresenta como princípios da Articulação por uma Educação Básica do Campo, essa luta por uma educação enquanto direito, compreendendo que: "Direitos se concretizam no espaço público e não no privado. Não podemos aceitar a 'privatização dos direitos' que vem acontecendo na sociedade capitalista neoliberal." (ARROYO; FERNANDES, 1999, p.78, grifos no original).

Outro aspecto muito importante dessa construção de uma proposta de Educação do Campo via movimentos sociais, pela base, é a da sua relação com a Educação Profissional. Ao longo do documento percebemos que há um entendimento do trabalho enquanto princípio educativo e de considerar a Educação como um meio para a formação humana integral, indo além da preparação para o trabalho do campo.

Compreendem o trabalho como modo em que os homens não apenas cultivam a terra e o seu produto, mas cultivam suas vidas, sua sociabilidade e produzem a si mesmos enquanto sujeitos. Arroyo (1999) em sua palestra na Conferência, que faz parte dos cadernos, "Por uma 
Educação do Campo", define como esse movimento dos campesinos compreende a relação entre educação e trabalho: "A cultura da roça, do milho, é mais do que cultura. É cultivo do ser humano. É o processo em que ele se constitui como sujeito cultural. Por isso, vocês não separam produção de educação, não separam produção de escolas" (ARROYO, 1999, p. 26).

Essa compreensão, inclusive, ia à contramão das propostas que o governo FHC tinha para a Educação Profissional naquele período. Posto que, enquanto os movimentos sociais estavam propondo criação de Escolas Técnicas Regionais, combinando ensino profissional ao propedêutico, nos termos do que temos hoje como Ensino Médio Integrado, o governo federal no mesmo ano estava inviabilizando essa proposta ao editar o Decreto $n^{\circ}$ 2.208/98 já citado nesse trabalho.

A relação entre educação e trabalho, sob essa perspectiva do movimento campesino nos traz à tona a discussão de Saviani (2007) que resgata a dimensão ontológica e histórica do trabalho e da educação, o que é coerente com os fundamentos dos grupos contra-hegemônicos que disputam em nosso país uma concepção de Educação Profissional compreendendo-a como meio para formação humana integral e emancipação dos trabalhadores, concepção adotada por essa pesquisa.

Inclusive, essa aproximação entre Educação do Campo e Educação Profissional foi essencial para a pedagogia soviética na construção da Escola Politécnica para o período de transição ao Socialismo, nos anos 1920. Para Pistrak (2005) a escola do campo poderia, inclusive, se tornar de forma mais rápida uma escola do trabalho graças ao cotidiano familiar, a economia e o círculo cultural dos camponeses, pois as crianças entram diretamente e muito mais cedo no trabalho agrícola produtivo. Para além disso, a agricultura é por si só um complexo de diferentes tipos e ramos de produção, o que este autor chamou de "conjunto politécnico peculiar". A escola do campo teria, então, centralidade na discussão da pedagogia soviética que objetivava fazer dessa escola "uma das alavancas para superar as contradições entre campo e cidade e, desta maneira, dar à escola do campo um grau de eficácia que a escola urbana não tem e não pode revelar" (PISTRAK, 2005, p. 44).

O Movimento Por Uma Educação Básica do Campo ganhou muita força no seio de toda sociedade, porém, mesmo com a abertura de um novo circuito histórico, com a eleição do 
campo popular através do Partido dos Trabalhadores para a presidência da república em 2003, alguns fenômenos de ordem estrutural e as opções políticas deste governo frente a esses fenômenos, possibilitaram uma nova virada de paradigma no campo com o fortalecimento do agronegócio.

Já discutimos aqui que com o processo da restruturação produtiva, o capital financeiro passou a ser essencial para o retorno das taxas de lucro que tiraram as economias da grande crise da década de 1970. Esse fenômeno da financeirização ganhou o mundo, e como explica Fatorelli (2013) os anos 1990 foram primordiais para tal, pois, as últimas amarras foram retiradas dos bancos para realizarem quase todos os tipos de transações financeiras: criação de derivativos ${ }^{4}$ e produtos de investimento, e a desregulamentação financeira que quebrou a separação obrigatória entre bancos de depósitos e bancos de investimentos - política esta construída a partir do Consenso de Washington, que foi se tornando ao longo dos anos 1990 em agenda política do FMI.

Esse fenômeno mundial recolocou a agricultura, em países como o Brasil, novamente no projeto do grande capital, ao tratá-la como commodities agrícolas, como investimento, o que atrela estas também a rentabilidade, mexendo novamente no mundo do campo, o que terá suas implicações para a educação.

O capital financeiro entra, então, na agricultura e para a roda da economia do capital girar é necessário um grande volume de crédito circulando. Nesse sentido, o Brasil entra novamente num ciclo de modernização da agricultura, no modelo do agronegócio.

Para maior produtividade, voltamos à prevalência do modelo das monoculturas e agora com uso maior de tecnologias voltadas para fertilizantes e agrotóxicos, bem como, maior exploração da força de trabalho dos assalariados do campo. Essa combinava, assim, o moderno da mecanização com práticas de trabalho escravo ou análogo a este. Para maior rentabilidade, requeria adiantamento de crédito para compra de sementes e insumos.

\footnotetext{
${ }^{4}$ Produtos bancários inconsistentes, mas que proporcionaram ganhos fabulosos aos bancos, pois ao serem contabilizados no balanço dos bancos inflam artificialmente seus resultados, aumenta sua liquidez e permite concessão de novos empréstimos, desvinculando os produtos financeiros da produção de valor real na sociedade.
} 


\section{Revista \\ Debates Insubmissos}

O Relatório do Fórum Nacional da Educação do Campo (FONEC) de 2012, (BRASIL, 2012), que analisa a situação do campo no Brasil nos últimos anos sintetiza bem o novo papel da agricultura nesse modelo para a inserção do Brasil nessa economia mundial:

Agora a agricultura, na lógica do agronegócio, passa a ter uma expressiva função econômica no modelo capitalista em curso: gerar saldos comerciais para ampliar as reservas cambiais, condição essencial para atrair os capitais especulativos para o Brasil (BRASIL, 2012, p.7).

Ainda segundo o Fórum, foi refeito um pacto das classes dominantes no Brasil para sustentar essa nova hegemonia de campo, aliando-se então grandes proprietários modernizados, transnacionais e com capital financeiro e mídia.

Esse período coincide com a abertura de um novo circuito histórico no Brasil, onde o campo popular chega à presidência da república com a eleição do Partido dos Trabalhadores em 2002. Partido esse que esteve sempre vinculado aos movimentos sociais do campo. Todavia, é importante lembrar que a sua chegada ao poder advém para além das urnas, de um pacto com parte das elites brasileiras, expressada com a "Carta ao povo Brasileiro" de $2002^{5}$.

Nesse sentido, esse ciclo de hegemonia do modelo do agronegócio e do governo do Partido dos Trabalhadores é um período de movimentos contraditórios para o campo e para a educação do campo, assim como, já mencionamos, foi também para a Educação Profissional.

A força política do Movimento Por uma Educação Básica do Campo, nesse período conseguiu, aprovar na Lei de Diretrizes e Bases da Educação (Lei n 9394/96) o calendário das Escolas do Campo a sua especificidade dos tempos da produção e colheita ; a criação do Fórum de Educação do Campo; a transformação da Coordenação-Geral de Educação do Campo do MEC na Secretaria de Educação Continuada, Alfabetização e Diversidade (SECAD); o Programa Nacional de Educação na Reforma Agrária (PRONERA) e já nesse final de ciclo a ampliação e criação de vários cursos de Licenciatura para a Educação do Campo, via Pronacampo, Programa no qual se insere o Pronatec Campo, objeto de análise dessa pesquisa.

\footnotetext{
${ }^{5}$ O Jornal Folha de São Paulo inclusive divulgou a carta com o seguinte título "Leia íntegra da carta de Lula para acalmar o mercado financeiro" (FOLHA ONLINE, 2002).
} 
Apesar desses avanços, todos conquistados com muita luta e disputa por essa articulação, esse momento de hegemonia do agronegócio representou perdas de direitos e o não avanço em pautas históricas do movimento como, por exemplo, a Reforma Agrária.

Demonstramos há pouco, como há um entendimento claro para os movimentos sociais do campo que para prosperar um projeto de desenvolvimento do campo sustentável e humanizado, bem como de Educação do Campo para tal, é necessário Reforma Agrária. No entanto, esta sequer foi ensaiada, mesmo com o governo do campo popular, pois, nesse novo papel do campo, do agronegócio modernizado, para o capital internacional, a posse de grandes terras improdutivas é primordial para uma expansão da produção.

Somado a esse processo de modernização, que amplia o fluxo migratório e a disputa com o agricultor familiar por espaço no campo, outro fator de grande retrocesso identificado é o fechamento das Escolas do Campo. Segundo dados do Grupo de Estudos e Pesquisas sobre Educação no Campo (GEPEC) da Universidade de São Carlos (UFSCAR):

\footnotetext{
Das mais de 100 mil escolas rurais que existiam em 2002 no Brasil, 17 mil foram fechadas. Isso representou, nas regiões Sul e Centro-Oeste, uma redução de mais de $39 \%$, seguidas pela região Nordeste $(22,5 \%)$, Sudeste $(20 \%)$ e Norte $(14,4 \%)$. Neste mesmo período, o número de matrículas reduziu de 7,9 para 6,6 milhões de educandos, o que representa mais de 1,2 milhão de pessoas sem escola ou obrigadas a estudar nas cidades. (FUNDAÇÃO DE APOIO INSTITUCIONAL DE DESENVOLVIMENTO CIENTÍFICO DA UFSCAR, 2017)
}

Essa situação do fechamento de escolas é gravíssima e implica necessariamente em expulsão da população do campo, como bem menciona Silva (2017), muitas vezes, a escola é a única intervenção estatal em certas comunidades, a Escola do Campo é um espaço não apenas de formação, mas também de reunião e integração da comunidade.

Nessa perspectiva de avanços e retrocessos, o Fonec (BRASIL, 2012) analisa que as ações do Pronacampo, num âmbito geral, vêm recolocando uma perspectiva de Educação Rural para a população do campo. Compreendendo que os avanços e mudança de paradigma do Movimento Por uma Educação do Campo se deu para além da forte mobilização e articulação, mas em um momento em que havia ausência total do Estado no Campo e de decadência do pacto das elites que perdurou até a ditadura. Por isso, no presente momento em 


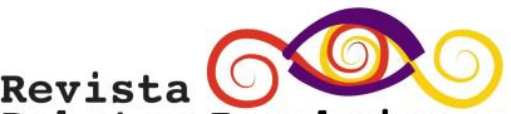 \\ Debates Insubmissos}

que o campo tem outra importância para essas elites, envolvendo novas ações do Estado em prol destas, há um retorno mais agudo da perspectiva da Educação Rural.

No presente momento, o modelo do agronegócio, ao compreender a importância da educação na construção de sua hegemonia, passa a investir também nessa área, se aproveitando da sua grande inserção e possibilidade de aprovação de políticas públicas, frente ao seu volume de capital e modelo de financiamento de campanhas eleitorais no Brasil. Quando falamos de hegemonia é justamente nos termos de Gramsci (1980) na perspectiva de disputa pelo controle estatal, a disputa de poder através do elemento do convencimento, da guerra de posição na tentativa de ocupar trincheiras, espaços sociais vitais para essa hegemonia.

A despeito disso, a empresa campeã de financiamento das campanhas eleitorais para os presidenciáveis na última eleição no Brasil, 2014, foi a JBS, dona do frigorífico Friboi, um dos grandes representantes do agronegócio, reconhecida como uma das maiores exportadoras de carnes do mundo. Segundo o jornal Folha, ela doou 391 milhões de reais para campanhas eleitorais em 2014, sendo que a segunda maior doadora investiu 111 milhões, ou seja, três vezes menos (TERENZI; URIBE; AZEVEDO; 2014). É interessante notar o papel que as doações de campanha ocupam no nosso atual modelo democrático, onde, 3 anos após o pleito, os maiores escândalos de corrupção ${ }^{6}$ do atual momento histórico do país, envolvem agentes políticos do governo e executivos das duas maiores doadoras, com repasses bilionários do Tesouro Nacional ao Banco Nacional de Desenvolvimento Econômico e Social (BNDES), que por sua vez realizava empréstimos a juros muito baixos a estas.

A questão da construção de hegemonia é tão central hoje ao Agronegócio que nunca se viu tantas inserções de propagandas deste nos maiores canais de comunicação no país. A Rede Globo, maior empresa de comunicação do país tem diversas propagandas em horário nobre da Campanha “Agro: a Indústria-Riqueza do Brasil”. Campanha esta que conta com um hotsite exclusivo hospedado no Site G1, do Grupo Globo, um dos canais virtuais de maior

\footnotetext{
${ }^{6}$ JBS supera Odebrecht e vai pagar maior multa da história por corrupção (REGIANE, 2017). Segundo a Associação Contas Abertas (2017), o dinheiro investido por essas empresas em esquemas de corrupção, aproximadamente 3 bilhões, poderia servir para construir 1.579 creches, que poderiam atender quase 253 mil crianças, comprar cerca de 24.440 ambulâncias, construir quase 2.143 Unidades de Pronto Atendimento, ou construir 7.500 Unidades Básicas de Saúde.
} 
acesso do país. As propagandas ressaltam a todo o momento o slogan "Agro é tech, agro é pop", tentando criar uma imagem moderna ao Agronegócio e gerar uma simpatia por parte da população. O site StartAgro, destaca esse momento de construção de uma marca do Agronegócio brasileiro, ressaltando a fala do diretor de Marketing da TV Globo:

\begin{abstract}
De acordo com Schmidt, o objetivo da iniciativa é conectar o consumidor com o produtor rural e ao mesmo tempo desmistificar a produção agrícola aos olhos da sociedade urbana. "Queremos mostrar que a riqueza gerada pelo agronegócio movimenta os outros setores da economia", salientou, acrescentando que: "a ideia é fazer com que o brasileiro tenha orgulho do agro" (START AGRO, 2017, grifos no original).
\end{abstract}

Vivemos um momento de avanço da perspectiva de uma Educação Rural, com fins de legitimar o modelo do agronegócio, de convencer a população de seus benefícios, e para o Fonec (BRASIL, 2012), boa parte dessa perspectiva se materializa com o Pronatec Campo. Outro elemento importante nessa construção de hegemonia do modelo do agronegócio é o processo de criminalização dos movimentos sociais do campo (BRASIL, 2012), para reduzir seu poder de influência sobre o governo, bem como diminuir o apoio popular às pautas e movimentações deste.

Apesar desse avanço do agronegócio enquanto modelo de campo para nosso país, em atendimento aos interesses do capital internacional e ao novo pacto das elites do Brasil, esse movimento engendra em si contradições que, como diria Marx e Engels (2008) são a própria arma contra si.

A necessária expulsão do camponês para a ampliação do monocultivo modernizado já gera ausência de força de trabalho para o agronegócio, bem como, a necessária vinculação dessa forma de produção ao uso de agrotóxicos e insumos que em troca da rentabilidade comprometem a segurança alimentar, impulsiona a "existência e propagação de outro modo de agricultura que não apresenta as mesmas implicações que as suas” (BRASIL, 2012, p.11), a agricultura familiar camponesa.

A existência dessas contradições mantém vivo e forte o já mencionado projeto de desenvolvimento do campo e de uma educação do campo para o país, consolidado no final dos anos 1990, com o ENERA e a Conferência Nacional Por uma Educação do Campo, e a 
existência desse campo contra-hegemônico permite que os movimentos do governo, não apenas retrocedam face a esse projeto, mas também realizem concessões e avanços.

O Pronatec Campo é também resultado dessas contradições. O Fonec, em seu já citado relatório de 2012, aponta, por exemplo, que foi uma política que não passou por discussão com os movimentos do campo antes do seu lançamento, sendo discutido internamente apenas. E algo muito custoso para esse movimento é a participação nas diversas etapas do ciclo da política, não é à toa que um dos seus princípios é uma gestão democrática das políticas, da educação, e também, o tratamento dos povos do campo como sujeitos de direitos.

Interessante notar que os debates que perpassam a análise do Pronatec Campo no Fonec (BRASIL, 2012) têm o mesmo sentido de nossas indagações em uma discussão sobre o Pronatec geral (SANTOS, 2018), quais sejam, diante do contexto em que vivemos de desemprego estrutural, de avanço da lógica do privado na educação e manutenção de um modelo de educação dual. O Pronatec é concessão da classe dominante e do Estado frente às lutas e demandas populares, ou forma de reprodução e ampliação do pensamento hegemônico? A esse questionamento, respondido em Santos (2018) o Fonec, foi enfático e apresentou a seguinte perspectiva:

O Pronatec Campo se insere no mesmo quadro, sendo apresentado pelo governo à sociedade como uma grande conquista: também aos trabalhadores do campo a democratização do acesso ao ensino técnico e a possibilidade de 'inserção produtiva'. Trata-se de mais uma ferramenta da estratégia de construção da hegemonia da agricultura capitalista que se pretende seja dominante (e para muitos, única) De um lado é a preparação de mão-de-obra para o trabalho mais desqualificado que o agronegócio demanda (e que quantitativamente é pequena). E note-se que não estamos no âmbito das demandas de formação profissional de trabalhadores de ponta das empresas (transnacionais) que concentram o domínio do agro (demandas que quantitativamente são menores ainda). (BRASIL, 2012, p.18).

Reforça também outro grande problema da lógica privatista desse Programa, já tratados por nós, que seria além do envio de dinheiro público para instâncias privadas, a terceirização da perspectiva de educação que está sendo destinada aos trabalhadores. Nessa, estes ficam destinados a receber uma educação voltada ao mercado, instrumental e pragmática, muito distante da proposta de educação emancipatória do movimento Por uma Educação Básica do Campo. Nesse sentido, encontramos no Relatório (BRASIL, 2012), de forma subentendida 


\section{Revista \\ Debates Insubmissos}

uma breve lição sobre a confiança em governos, ainda que advindos de suas fileiras de luta, diante da forma de Estado na qual vivemos hoje:

A construção de uma perspectiva de educação emancipatória, vinculada ao esforço de luta por uma república do trabalho, precisa ser obra dos próprios trabalhadores, com radicalidade de princípios e de concepção, com autonomia e sem a tutela política, organizativa e pedagógica do Estado, seja quais forem os governos de plantão (BRASIL, 2012, p. 24).

Apesar dessa compreensão e por entendermos a importância dos processos de luta e de disputa por hegemonia, reconhecemos também as possibilidades do Pronatec, quando realizado por instituições públicas com Projetos Pedagógicos e Ações voltadas para uma educação emancipatória, para uma educação profissional na perspectiva da formação humana integral, reconhecendo o papel do Pronatec no quadro de avanço da dualidade estrutural, mas ressalvando suas possibilidades:

Trata-se de uma inclusão às avessas que acaba sendo mais uma ferramenta da construção de hegemonia da estratégia de destruição como camponeses. Não são cursos um mal em si mesmos e nem pode o programa ser rechaçado em bloco. Entendemos que especialmente as brechas de inserção dos institutos federais em desafios de formação dos trabalhadores do campo, podem ser potencializadas na direção de outro paradigma. Mas as organizações dos trabalhadores estão atentas: O Pronatec Campo, até pelos atores privilegiados envolvidos (CNA, Senar), integra uma estratégia determinada, que é muito mais de cooptação dos trabalhadores à lógica do agronegócio do que de inserção social, ainda que enviesada, como é a lógica do Pronatec em seu conjunto (BRASIL, 2012, p. 20, grifos nossos)

Ainda sobre as possibilidades de inserção dos Institutos Federais e demais instituições públicas, quando do início da implementação do Pronatec, a Confederação Nacional dos Trabalhadores Rurais e Agricultores e Agricultoras Familiares (CONTAG) exigiram ao MEC que esse quadro da oferta do Pronatec fosse invertido, cobrando inserção maior de Instituições públicas no lugar do Sistema S:

A CONTAG não concorda com o fato de o Senar ser majoritário na oferta desses cursos. No final do ano, a presidenta Dilma Rousseff aumentou o número de entidades ofertantes dos cursos. Mesmo assim, ficou muito restrito, principalmente quanto às escolas de alternância", reforçou José Wilson. Os representantes do MEC informaram que houve avanço recentemente com a inserção das Escolas Famílias Agrícolas no Fundeb. "Agora, é preciso que essas escolas sejam reconhecidas pelos Conselhos Estaduais de Educação", orientaram. Eles informaram ainda que a rede pode ser ampliada a partir das universidades públicas, e que os institutos federais e 


\title{
nevistet \\ Debates Insubmissos
}

\begin{abstract}
escolas técnicas estaduais já estão ofertando cursos pelo Pronatec. (CONFEDERAÇÃO NACIONAL DOS TRABALHADORES RURAIS E AGRICULTORES E AGRICULTORAS FAMILIARES, 2013, p.1).
\end{abstract}

Nesse sentido, cabe ainda investigar se essa inserção dos Institutos Federais e Universidades públicas na oferta do Pronatec Campo pode ou pôde ser uma possibilidade de deslocar esta política do paradigma da Educação Rural para o da Educação do Campo, fazendo então do Pronatec Campo um espaço de disputa, ou trincheira, nos termos da disputa por hegemonia em Gramsci (1980), uma vez que, no contexto ora analisado neste artigo essa política se aproxima muito mais de uma retomada às bases e ações da Educação Rural.

A partir dessa trilha, Santos (2018) realizou uma avaliação participativa dos resultados sociais do Pronatec Campo ofertado no Instituto Federal de Ciência e Tecnologia do Rio Grande do Norte (IFRN), onde entrevistou gestores do MDA, do IFRN, e realizou grupos focais com os sujeitos do campo que participaram do Programa juntamente com seus professores.

Essa avaliação apresenta em primeiro plano, e no início de sua exposição movimentos contra-hegemônicos dos povos do campo, na perspectiva de aproximar o Pronatec dos Paradigmas da Educação do Campo, especificamente ao tratar de que no Rio Grande do Norte, foi o Movimento Social do Campo que demandou os cursos ofertados no Pronatec Campo, dessa forma é possível aferir que:

[...] o Pronatec Campo tem feições bem distintas do Pronatec Geral no qual ele está incluso, e isso se deu por fatores importantes, um deles foi o fato deste ter sido uma demanda dos povos do campo. Em nossas entrevistas com os gestores da Delegacia do MDA no Rio Grande do Norte, foi possível ouvir a confirmação de que os movimentos sociais do campo exigiram do governo que chegasse ao campo uma política diferente daquela, inclusive já estava ali no campo, pois já era ofertado o Pronatec Geral àqueles sujeitos. (SANTOS, 2018, p. 118).

Com essa ação, os sujeitos do campo foram incluídos no período de tomada de decisão da política, e esse envolvimento dos sujeitos tem como fundamento a compreensão da valorização do povo do campo como sujeitos de sua própria história, que é também base do paradigma da Educação do Campo.

Essa avaliação identificou também como resultado social do Pronatec Campo em um Instituto Federal o despertar de um interesse nesses sujeitos por ocupar aquele espaço de 
educação considerado de qualidade, tanto eles mesmos, quanto seus filhos e filhas, realizando outros cursos e/ou concluindo o Ensino Médio (SANTOS, 2018).

Apesar desses aspectos positivos, a pesquisa citada mostra que mesmo com todos os esforços, as dificuldades e limitações de um Programa que tem como base cursos de Formação Inicial e Continuada, com carga-horária bastante reduzida, não permitem que esta oferta ultrapasse o status de qualidade social mitigada (SANTOS, 2018), e aponta ainda que isso ocorre num dos melhores cenários, que é da oferta em um Instituto Federal.

Dentre as dificuldades e limitações avaliadas pelos sujeitos na pesquisa estão: tempo reduzido; poucas aulas práticas; acompanhamento extraclasse não suficiente; insuficiência de tempo para os trâmites de aquisição de material e liberação dos recursos; ausência de uma perspectiva de Economia Solidária; problemas constantes com transporte escolar (fornecido pelas prefeituras); ausência de políticas públicas para a execução e aplicação do conhecimento aprendido com atividades após os estudos; ausência de perspectiva de continuidade nas ações; pouca carga horária para disciplinas como ética, economia, direito e história da agricultura; e aulas realizadas foram do ambiente da comunidade rural e o consequente deslocamento dos sujeitos até o campus.

Ainda no terreno das contradições, no processo de coleta de dados, Santos (2018) investiga se os temas que constam dos objetivos específicos do Pronatec Campo, como agroecologia, agricultura familiar e segurança alimentar, que são também demandas do paradigma da Educação do Campo, (KOLING; NERY; MOLLINA, 1999), se foram abordados no curso, e percebe, então, que a Delegacia do MDA local solicitou isso dos ofertantes, que o IFRN, locus da pesquisa deu conta dessa abordagem, porém, ainda segundo os gestores do MDA, isso não foi uma realidade na maioria das ofertantes.

Dessa forma, o trabalho de Santos (2018) conclui que apesar dos movimentos contra hegemônicos da população do campo e dos atores do Estado envolvidos nessas ações, em aproximar o Pronatec Campo das demandas do Paradigma da Educação do Campo, em contraposição ao Paradigma da Educação Rural, e em diferenciar essa forma de Pronatec do Pronatec Geral, e disputar um modelo de política pública de educação para atender suas demandas e seu projeto, na esteira da oferta desses Programa em uma Instituição Pública, 


\section{Revista
Debates Insubmissos}

reconhecida pela qualidade da sua educação, o formato padrão de curso FIC do Pronatec não permitiu que estes avançassem nessa disputa, e para além disso, aponta ainda que essa oferta, com todas as contradições, e com um meio avanço, representa menos de $1 \%$ da oferta do Pronatec Geral.

\section{CONCLUSÕES}

O Pronatec Campo, situado no contexto histórico de disputa por hegemonia e construção de um projeto de desenvolvimento do Campo e por Educação do Campo, encontra-se em um quadro político contraditório de avanços e retrocessos em políticas públicas para essa Educação. No entanto, no desenho do Pronatec Campo como política e em seus atos normativos são apresentadas as perspectivas e demandas da população do campo, muitas inclusive constam dos documentos da Articulação por uma Educação Básica do Campo (KOLING; NERY; MOLLINA, 1999).

Esta política tem reproduzido uma perspectiva de Educação Rural, a qual se contrapõe às demandas e projetos da população do campo. Isso porque se encontra articulado e imerso em um quadro político mais amplo de disputa ideológica que tem como modelo o Agronegócio com grande peso político dentro e fora do Estado, e mesmo com esse desenho que tende a mitigar interesses, a política mantém o padrão do Pronatec Geral para a Educação Profissional no que tange a oferta de cursos de curta duração, aligeirados e ofertados em sua maioria por entes privados.

Por fim, como complemento a esta análise, resta ainda analisar a trincheira, tratada como brecha pelo Fonec (BRASIL, 2012), de forma empírica para superar o senso comum e a aparência do programa como uma concessão, uma benesse ao povo brasileiro, à população do campo, para desconstruir o mito da empregabilidade e identificar os reais interesses dos setores que construíram essa política.

Sendo assim, negar e superar a análise estrutural, sem desconsiderá-la, compreendendo a pulsão e a vida dos processos sociais e suas possibilidades é explicar o objeto de estudo analisando as mediações entre os diversos níveis de totalidade e seu desenvolvimento no processo histórico, para construir conhecimento sobre o Pronatec Campo, com fundamentos 
no materialismo-histórico-dialético, posto que por meio desse método podemos explicar suas contradições, limites e possibilidades. Para que assim, possamos nos munir de informações para reiniciar a pensar o ciclo do Pronatec Campo como uma política pública com uma agenda que atenda realmente os interesses das camadas sociais que disputam hegemonia na perspectiva da superação de classes e consequentemente das desigualdades sociais.

\section{REFERÊNCIAS}

ARROYO, Miguel. A Educação Básica e o Movimento Social do Campo. In: Arroyo, Miguel Gonzalez; FERNANDES, Bernardo Mançano. A Educação Básica e o Movimento Social do Campo. Brasília: Articulação Nacional por uma Educação Básica do Campo, 1999. p. 15-52. (Coleção Por uma Educação Básica do Campo, n.2)

Introdução: Os coletivos repolitizam a formação. In: DINIZ-PERERA, Julio Emílio; LEÃO, Geraldo (Org.). Quando a diversidade interroga a formação docente. Belo Horizonte: Autêntica, 2008. p. 11-36.

ARROYO, Miguel. FERNANDES, Bernardo Mançano. A Educação Básica e o Movimento Social do Campo. Brasília: Articulação Nacional por uma Educação Básica do Campo, 1999. (Coleção Por uma Educação Básica do Campo, n.2)

BRASIL. Notas para análise do momento atual da Educação do Campo. Fórum Nacional de Educação do Campo (FONEC). Seminário Nacional. 15 a 17 ago. Brasília, 2012, p. 01-28. Disponível em: < http://ww.gepec.ufscar.br/textos-1/legislacao1/forum-nacional-de-educacaodo-campo-2013-fonec-notas-para-analise-do-momento-atual-da-educacao-docampo/at_download/filef> Acesso em 5 ago. 2017

Ministério do Desenvolvimento Agrário. Cartilha Pronatec Campo. Brasília, 2013. Disponível em: <http://www.mda.gov.br/sitemda/sites/sitemda/files/user_img_23/cartilha\%2 OPRONATEC_baixa.pdf> Acesso em 10 ago. 2017

CONFEDERAÇÃO NACIONAL DOS TRABALHADORES RURAIS AGRICULTORES E AGRICULTORAS FAMILIARES. CONTAG e MEC negociam pontos referentes à Educação do Campo 2013. [Matéria disponibilizada em 17 de maio de 2013, na internet]. Brasília, 2013. Disponível em: <http://www.contag.org.br/indexdet2.php? modulo=portal\&acao=interna2\&codpag=101\&id= 8740\&data $=17 / 05 / 2013 \& \mathrm{nw}=1 \& \mathrm{mt}=1 \&$ ano=2013\&mes=05> Acesso em 8 ago 2017

COTTA, Tereza Cristina. Metodologia de avaliação de programas sociais: análise de resultados e de impactos. Revista do Serviço Público, Brasília, v. 49, n. 2. p. 105-126, abr./jun. 1998. 
FUNDAÇÃO DE APOIO INSTITUCIONAL DE DESENVOLVIMENTO CIENTÍFICO DA UFSCAR. Fechamento de escolas rurais é reflexo de luta de classes. [Artigo disponibilizado em 17 de março de 2017, na internet] São Carlos, 2017. Disponível em: <http://www.fai.ufscar.br/noticia/fechamento-de-escolas-rurais-e-reflexo-de-luta-declasses.html> Acesso em 10 ago. 2017

FATORELli, Maria Lucia. Auditoria Cidadã da Dívida Pública: Experiências e Métodos. Brasília: Inove Editora, 2013.

FOLHA ONLINE. Leia íntegra da carta de Lula para acalmar o mercado financeiro [Matéria disponibilizada em 24 de junho de 2002, na internet]. 2002. Disponível em: http://www1.folha.uol.com.br/folha/brasil/ult96u33908.shtml Acesso em 20 nov. 2017

GRAMSCI, Antonio. Maquiavel, a política e o Estado Moderno. Rio de Janeiro: Civilização Brasileira, 1980.

HADDAD, Sergio. O direito à educação no Brasil. Relatoria Nacional para o Direito Humano à Educação. Curitiba: DhESC Brasil, 2004.

KOLLING, Edgar Jorge; NERY, Irmão; MOLINA, Mônica Castagna. Por uma educação básica do campo. Brasília: Ed. Universidade de Brasília, 1999. (Coleção Por uma educação do campo, n. 1).

MARX, Karl. Contribuição à crítica da Economia Política. São Paulo: Expressão Popular, 2008.

MARX, Karl; ENGELS, Friederich. Manifesto do Partido Comunista. São Paulo: Expressão Popular, 2008.

MAZOYER, Marcel; ROUDART, Laurence. História das Agriculturas no mundo: do neolítico as crises contemporâneas. São Paulo: Unesp, 2015.

MELLO NETO, João Cabral de. Morte e vida Severina. Rio de Janeiro: Objetiva: 2009.

OLIVEIRA, Regiane. JBS supera Odebrecht e vai pagar maior multa da história por corrupção. 2017. [Matéria disponibilizada em 31 de maio de 201, na internet] 2017. Disponível

em:

<https://brasil.elpais.com/brasil/2017/05/31/politica/1496247279_854999.html> Acesso em: 20 nov. 2017

PISTRAK, Moisey M. Ensaios sobre a Escola Politécnica. São Paulo: Expressão Popular, 2005.

SANTOS, Shilton Roque dos. Avaliação participativa de resultados sociais do PRONATEC Campo. 2018. 168f. Dissertação (Mestrado em Educação Profissional) Instituto Federal de Educação, Ciência e Tecnologia do Rio Grande do Norte, Natal, 2018. 
SAVIANI, Demerval. Trabalho e educação: fundamentos ontológicos e históricos. Revista Brasileira de Educação, Rio de Janeiro, vol.12, n.34, p.152-165, 2007.

SILVA, Kize Arachelli de Lira. Concepções e práticas da educação do campo: um estudo com professores em formação. 2017. 325f. Tese (Doutorado em Educação) - Centro de Educação, Universidade Federal do Rio Grande do Norte, Natal, 2017.

SOUZA, Lincoln Moraes de. Três ensaios sobre avaliação de políticas públicas. Natal: EDUFRN, 2014.

STAR TAGRO. Por que a Globo criou a campanha "agro é tech, agro é pop". [Matéria disponibilizada em 5 de abril de 2017, na internet]. 2017 Disponível em: < http://www.startagro.agr.br/por-que-o-agronegocio-precisa-de-uma-comunicacao-moderna/> Acesso em 20 nov. 2017

STEINBECK, John. As Vinhas da Ira. Rio de Janeiro: Abril, 1972.

TERENZI, Gabriela; URIBE, Gustavo; AZEVEDO, Rayane. Custo de R\$ 5 bilhões faz eleições deste ano baterem recorde histórico. [Matéria disponibilizada em 30 de novembro de 2014, na internet]. 2014. Disponível <http://www1.folha.uol.com.br/poder/2014/11/1555475-custo-de-r-5-bilhoes-faz-eleicoesdeste-ano-baterem-recorde-historico.shtml> Acesso em 20 nov. 2017

Submetido em: $15 / 10 / 2018$

Aprovado em: 08/12/2018 